Кузьмич В. I. , orcid.org/0000-0002-8150-3456

Кузвмич А. В. , orcid.org/0000-0002-6727-9064 Савченко О. Г., orcid.org/0000-0003-4687-5542

\title{
ВИКОРИСТАННЯ ЕЛЕМЕНТІВ ГЕОМЕТРІї ПІД ЧАС ВИВЧЕННЯ СТУ ДЕНТАМИ МЕТРИЧНИХ ПРОСТОРІВ
}

Вивчення метричних просторів студенти фізико-математичних спеціальностей узакладах вищої освіти розпочинають, як правило, на другому курсі під час студіювання функцій багатьох змінних. Це вивчення значною мірою присвячене диференціальним та інтегральним властивостям ичих функцій у різних метричних просторах.

У роботі пропонуеться використання елементів метричної геометрії для поглиблення знань здобувачів освіти із властивостей метричних просторів під час їх вивчення на фізикоматематичних спецііальностях педагогічного спрямування. Такий підхід зумовлений стрімким розвитком метричної геометрії у сучасній математиць та широким ї̈ застосуванням у різних галузях науки і навіть економіки. Значна частина матеріалу класичної геометрії Евкліда може бути представлена у вигляді аналітичних співвідношень між їі основними поняттями: точка, відстань між точками, кут, відрізок. Прикладом може слугувати класична теорема Піфагора про співвідношення між довжинами сторін прямокутного трикутника.

У даній статті, на основі аксіом відстані між точками метричного простору, наведені окремі аналітичні співвідношення, щзо носять геометричний характер у геометрії Евкліда. Відтак виникае можливість геометричної структуризації метричних просторів. Це дає змогу здобувачам освіти вивчати иі простори з геометричної точки зору, будуючи в них образи класичних геометричних понять.

Частина запропонованого у статті матеріаху, внаслідок його простоти, може бути використана під час роботи з учнями класів із поглибленим вивченням математики у закладах середньої освіти. 3 изією метою у роботі розглядаються специфічні означення прямолінійного розміщення точок метричного простору, кута, утвореного трьома точками простору, та його кутової характеристики. Вони значно спрощують сприйняття наведених результатів і дають можливість впровадження їх у шкільний курс математики.

Ключові слова: заклади загальної середньої освіти, профільний рівень навчання, позакласна робота з математики, геометрична компетентність.

Постановка проблеми. 3 метричними просторами студенти фізико-математичних спеціальностей закладів вищої освіти уперше знайомляться при вивченні $n$-вимірного евклідового простору у курсі математичного аналізу. Більш детально метричні простори вивчають у курсах теорії функцій та функціонального аналізу на математичних спеціальностях університету. При вивченні властивостей метричних просторів основну увагу звертають, як правило, на перевірку виконання аксіом відстані у конкретному просторі й мало уваги, на наш погляд, приділяють геометричним аспектам цих властивостей. Використання елементів метричної геометрії дає мождивість побудувати образи основних геометричних понять геометрії Евкліда у довільних метричних просторах. При цьому їхні геометричні властивості можуть змінюватись при зміні

*(C) Кузьмич В. I.

*(C) Кузвмич Л. В.

*C Савченко О.Г.

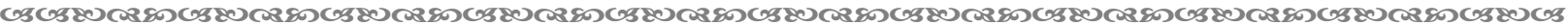


метрики простору. Однак, окремі аналітичні співвідношення, що носять геометричний зміст, виконуються у будь-якому метричному просторі.

До основних геометричних понять, що будуть розглянуті у цій роботі, ми відносимо відстань між двома точками метричного простору, прямолінійність розміщення точок та кут, що утворений трьома точками цього простору. Усі ці поняття базуються дише на трьох аксіомах метричного простору. Такий підхід дозволяе перенести окремі геометричні співвідношення геометрії Евкліда на випадок неевклідових геометрій, а також полегшить розуміння студентами основних геометричних понять.

Аналіз досліджень. Оскільки поняття метричного простору $є$ базовим у математиці, то поряд 3 метричними просторами здобувачами освіти також активно вивчаються їхні спеціальні класи та модифікації, що мають застосування у різних галузях сучасної науки [14-17].

Геометричні властивості метричних просторів розглядались у багатьох роботах. Поняття прямодінійного розміщення точок було введене В. Ф. Каганом [3, с. 527]. Це поняття вивчалось у роботах С. І. Галущак [1], А. А. Довгошея і В. Д. Дордовського [2], B. I. Кузьмича [4; 6]. У роботах $\quad$ В. I. Кузьмича i $\Lambda$. В. Кузьмич [5; 7] прямолінійне розміщення точок вивчалось за допомогою поняття кута, утвореного трьома точками метричного простору. Авторами статті встановлені аналітичні співвідношення, що мають певний геометричний зміст і виконуються у довільному метричному просторі [11]. Методика ознайомлення учнів, які навчаються у класах 3 поглибленим вивченням математики, і студентів закладів вищої освіти з найпростішими прикладами метричних просторів та елементами неевклідових геометрій, вивчалась у роботах В. І. Кузьмича і Л. В. Кузьмич [8; 10] та у роботах I. Lénárt i A. Rybak [12; 13].

Мета статті. Матеріал статті спрямований на розширення можливостей вивчення геометричних властивостей метричних просторів студентами фізико-математичних спеціальностей закладів вищої освіти. Відносно простий аналітичний апарат, що використаний у роботі, дає змогу розглядати основні геометричні образи у найпростіших метричних просторах на заняттях з учнями середніх та старших класів 3 поглибленим вивченням математики засобами інформальної та неформальної освіти.

Виклад основного матеріалу. Насамперед зауважимо, що при ознайомленні здобувачів освіти з елементами метричної геометрії будемо використовувати наступні означення метричного простору.

Означення 1. Метричним простором називають сукупність непорожньої множини Х елементів якої завгодно природи і дійсної функцї $\rho(x ; y)$, означеної для будь-яких елементів х і у з $X$, і яка задовольняе таким умовам:

1) $\rho(x ; y)=0$ mоді i лише тодi, коли $x=y$ ( $x$ i y збігаються),

2) $\rho(x ; y)=\rho(y ; x)$ (аксіома симетріi),

3) для будь-яких трьох елементів $x$, у і z виконуеться нерівність

$\rho(x ; y) \leq \rho(x ; z)+\rho(z ; y)$ (аксіома трикутника).

При цьому елементи множини $X$ називають точками метричного простору, функцію $\rho$ - метрикою простору $X$, а числове значення функції $\rho(x ; y)$ - відстанню між елементами (точками) $x$ і $y$. Метричний простір $X$ з метрикою $\rho$ позначають $(X ; \rho)$. Умови 1), 2) і 3) Означення 1 ще називають аксіомами відстані. Надалі усі точки метричного простору $(X ; \rho)$ будемо вважати попарно різними, тобто, будемо розгдядати лише додатні значення метрики $\rho$ простору $X$.

Означення 1 метричного простору студенти вивчають у курсі математичного аналізу та у курсі теорії функцій дійсної змінної [9, с. 436].

Поняття прямолінійності розміщення точок є частинним випадком Означення 1, у випадку, коли нерівність трикутника перетворюється у рівність [3, с. 527].

Означення 2. Будемо казати, що точки $x, y, z$ метричного простору $(X ; \rho)$ розміщені прямолінійно у иъвому просторі, якще виконуеться рівність 


$$
\rho(x ; y)=\rho(x ; z)+\rho(z ; y) .
$$

Можна дати здобувачам освіти означення прямолінійного розміщення множини точок метричного простору. Для цього слід вимагати від них прямолінійного розміщення будь-яких трьох точок цієї множини [5, с. 384].

Означення 3. Будемо констатувати, що множина точок метричного простору прямолінійно розміщена, якще будь-які три точки цุіё множини прямохінійно розміщені.

Далі розглянемо поняття прямодінійного розміщення точок метричного простору та поняття кута, утвореного трьома точками цього простору. Ці поняття дещо відрізняються від аналогічних понять, з якими здобувачі освіти знайомі зі шкільного курсу геометрії, однак зберігають основні ознаки відповідних класичних понять. Нижче буде встановлено зв' язок між цими поняттями та будуть вивчені їх окремі властивості.

Сукупність трьох точок $x_{1}, x_{2}, x_{3}$ простору називатимемо трикутником і позначатимемо $\Delta\left(x_{1}, x_{2}, x_{3}\right)$. При цьому, самі точки будемо називати вершинами, а пари точок $\left(x_{1}, x_{2}\right),\left(x_{1}, x_{3}\right),\left(x_{2}, x_{3}\right)$ - сторонами трикутника. У цій роботі будемо користуватись поняттям кута, утвореного трьома точками метричного простору [5, с. 383].

Означення 4. Нехай $x_{1}, x_{2}, x_{3}$ - довільні різні точки метричного простору $(X ; \rho)$. Упорядковану трійку $\left(x_{1}, x_{2}, x_{3}\right)$ изих точок будемо називати кутом з верииною у точцุi $x_{2}$ i позначати: $\angle\left(x_{1}, x_{2}, x_{3}\right)$. Пари точок $\left(x_{1}, x_{2}\right)$ i $\left(x_{2}, x_{3}\right)$, при извому, називатимемо сторонами кyma.

Оскільки у метричному просторі єдиною числовою характеристикою є відстань між точками простору, то за числову характеристику кута, що утворений трьома точками, слід вибрати дійсне число, яке можна обчислити за формулою косинусів у геометрії Евкліда [5, с. 383]. 3 цією формулою вперше учні детально знайомляться у 9-му класі.

Означення 5. Нехай $x_{1}, x_{2}, x_{3}$ - довільні різні точки метричного простору (X; $\rho$ ). Характеристикою кута $\angle\left(x_{1}, x_{2}, x_{3}\right)$, або кутовою характеристикою, будемо називати дійсне число $\varphi\left(x_{1}, x_{2}, x_{3}\right)$, що знаходять за формулою:

$$
\varphi\left(x_{1}, x_{2}, x_{3}\right)=\frac{\rho^{2}\left(x_{1}, x_{2}\right)+\rho^{2}\left(x_{2}, x_{3}\right)-\rho^{2}\left(x_{1}, x_{3}\right)}{2 \rho\left(x_{1}, x_{2}\right) \rho\left(x_{2}, x_{3}\right)} .
$$

Для спрощення і полегшення записів аналітичних перетворень здобувачами доцільно використовувати більш компактні позначення відстані між точками: $\rho\left(x_{i ;} ; x_{j}\right)=\rho_{i j}$ та кутової характеристики:

$$
\frac{\rho_{i j}^{2}+\rho_{j k}^{2}-\rho_{i k}^{2}}{2 \rho_{i j} \rho_{j k}}=\varphi_{i j k}(i, j, k=1,2,3, \ldots) .
$$

У випадку виконання рівності $\varphi_{123}=1$ кут $\angle\left(x_{1}, x_{2}, x_{3}\right)$ будемо називати «нудьовим», у випадку рівності $\varphi_{123}=-1-$ «розгорнутим», а у випадку рівності $\varphi_{123}=0-$ «прямим».

Поняття прямолінійного розміщення точок метричного простору досить просто можна записати аналітично за допомогою кутової характеристики [5, с. 384; 11, с. 88].

Означення 6. Будемо казати що точки хі, $x_{j}$, $x_{k}$ прямолінійно розміщені у просторі $(X ; \rho)$, якще рівність $\varphi_{i j k}^{2}=1$ виконується хоча б для однієї з циих точок (наприклад, для точки хі), як вершини кута $\angle\left(x_{1}, x_{2}, x_{3}\right)$.

Означення 6 дає мождивість здобувачам сформулювати поняття «внутрішніх» або «крайніх» точок за допомогою аналітичних виразів.

Використовуючи Означення 5, можна встановити ряд співвідношень для відстаней між точками метричного простору. Прикладом такого співвідношення може бути наступне твердження [5, с. 385]. рівність:

Теорема 1. Для довільних трьох різних точок $x_{1}, x_{2}, x_{3}$ простору $(X ; \rho)$ виконуеться 


$$
\left|\begin{array}{ccc}
1 & \varphi_{213} & -\varphi_{123} \\
\varphi_{213} & 1 & \varphi_{132} \\
-\varphi_{123} & \varphi_{132} & 1
\end{array}\right|=1-2 \varphi_{213} \varphi_{123} \varphi_{132}-\varphi_{213}^{2}-\varphi_{123}^{2}-\varphi_{132}^{2}=0 .
$$

Рівність, що наведена у Теоремі 1, можна розглядати як аналог відомого факту у геометрії Евкліда: сума внутрішніх кутів трикутника дорівнюе $2 \pi$. При знайомстві здобувачів з Теоремою 1 треба наголосити, що твердження теореми справедливе для довільного трикутника, навіть «виродженого», тобто у випадку прямодінійного розміщення трьох точок.

Теорема 2. Якщзо для трьох різних точок $x_{1}, x_{2}, x_{3}$ простору $(X ; \rho)$ виконуеться рівність: $\varphi_{123}=0$, то справедлива рівність:

$$
\rho_{13}^{2}=\rho_{12}^{2}+\rho_{23}^{2} \text {. }
$$

Теорему 2 можна розглядати як аналог теореми Піфагора для прямокутного трикутника у геометрії Евкліда [11, с. 89-90]. На прикладі цієї теореми бажано продемонструвати здобувачам тісний зв' язок геометрії з властивостями множини дійсних чисел.

Теорема 3. Якщо для чотирьох різних точок $x_{1}, x_{2}, x_{3}, x_{4}$ простору $(X ; \rho)$ виконуються рівності: $\varphi_{123}=-1, \varphi_{124}=\varphi_{324}=\varphi_{143}=0$, то справедлива рівність:

$$
\rho_{24}^{2}=\rho_{12} \rho_{23} \text {. }
$$

Теорему 3 можна розглядати як аналог для довільного метричного простору відомого твердження з геометрії Евкдіда про те, що довжина висоти, яка опущена 3 вершини прямого кута трикутника на його гіпотенузу, $\mathrm{e}$ середнім геометричним довжин відрізків, на які основа висоти ділить гіпотенузу [11, с. 90]. При знайомстві 3 цією теоремою здобувачам необхідно продемонструвати ії класичний аналог за допомогою відповідного рисунку.

Теорема 4. Для довільних трьох різних точок $x_{1}, x_{2}, x_{3}$ простору П виконуеться рівність:

$$
\rho_{13}=\rho_{12} \varphi_{213}+\rho_{23} \varphi_{132} .
$$

Зазначимо, що рівність в умові Теореми 4 е аналогом відомої у геометрії Евкдіда «формули проєкцій» [11, с. 90-91].

У результаті знайомства здобувачів освіти з Теоремами 1-4 та методами їх доведення вони повинні навчитись записувати окремі теореми класичної геометрії Евкліда у термінах метричної геометрії.

Висновки. Використання засобів метричної геометрії при вивченні метричних просторів дає мождивість геометричної інтерпретації властивостей цих просторів. Побудова геометричних образів у класичних метричних просторах дає мождивість провести їх структуризацію та більш детально вивчити властивості простору у залежності від його метрики. Зокрема, з'являється цілий клас задач на побудову геометричних структур у множині елементарних функцій.

Результати даної роботи можна використати при вивченні в університеті курсів елементарної геометрії, неевклідових геометрій, функціонального аналізу. Найпростіші елементи метричної геометрії, їі основні поняття можуть вивчатись у закладах середньої освіти при поглибленому вивченні математики. Для цього потрібно знайомити учнів із узагальненими поняттями точки, відстані між точками, прямодінійності розміщення точок. Це дасть можливість увести у шкільний курс математики основні поняття неевклідових геометрій.

Подальші дослідження можна проводити у напрямі виокремлення теоретичного та практичного матеріалу з елементами неевклідових геометрій, який може бути використаний для проведення математичного гуртка чи факультативу для учнів класів із поглибленим вивченням математики. 


\section{Список використаних джерел:}

1. Галущак С. I. Деякі геометричні криві у сенсі d-відрізка. Прикарпатський вісник НТШ. Число. 2016. № 1 (33). С. 157-166.

2. Довгошей А. А., Дордовский Д. В. Отношение лежать между и изометрические вдожения метрических пространств. Укр. мат. журн. 2009. Том 61, № 10. С. 1319-1328.

3. Каган В.Ф. Очерки по геометрии. Москва: Издательство Московского университета, 1963. $571 \mathrm{c.}$

4. Кузьмич В. І. Плоско розміщені множини точок у метричному просторі. Вісник Аьвівського університету. Серія механіко-математична. Дьвів: Видавництво Дьвівського національного університету імені Івана Франка. 2017. Випуск № 83. С. 58-71.

5. Кузьмич В. І. Геометричні властивості метричних просторів. Укр. мат. журн. 2019. Том 71, № 3. C. 382-399.

6. Кузьмич В. І. Формування в школярів понять відстані та прямолінійності засобами метричної геометрії. Педагогічний альманах : збірник наукових праць / редкол. В. В. Кузьменко (голова) та ін. Херсон: КВН3 «Херсонська академія неперервної освіти», 2019. Випуск 42. С. 43-50.

7. Кузьмич В. І., Кузьмич И.В. Формування поняття кута у шкільному курсі математики засобами метричної геометрії. Педагогічний альманах: збірник наукових праць / редкол. В. В. Кузьменко (голова) та ін. Херсон: КВНЗ «Херсонська академія неперервної освіти», 2020. Випуск 46. С. 56-63.

8. Кузьмич В. І., Кузьмич А. В. Формування понять точки, відстані та прямолінійного розміщення точок засобами метричної геометрії у 7-9 класах. Фізико-математична освіта. Суми: Сумський державний педагогічний університет імені А. С. Макаренка, 2020. Вип. 2 (24). C. 74-79.

9. Натансон И. П. Теория функций вещественной переменной. Москва: Наука, 1974. 480 с.

10. Kuz'mich V. I., Kuzmich L. V. Elements of non-Euclidean geometry in the formation of the concept of rectilinear placement of points in schoolchildren. J. Phys.: Conf. Ser. 2021. 1840 012004. DOI: https://doi.org/10.1088/1742-6596/1840/1/012004

11. Kuz'mich V. I., Savchenko A. G. Geometric relations in an arbitrary metric space. Математичні cmydii. 2019. Tом 52, № 1. C. 86-95. DOI: https://doi.org/10.30970/ms.52.1.76-85

12. Lénárt I. The Algebra of Projective Spheres on Plane, Sphere and Hemisphere. J. of Appl. Math. And Phys. 2020. V. 8, No 10. C. 2286-2333. DOI: $10.4236 / j a m p .2020 .810171$

13. Lénárt I. I., Rybak A. Comparative Geometry in Primary and Secondary School. The Pedagogy of Mathematics: Is There a Unifying Logic? Johannesburg: Mapungubwe Institute for Strategic Reflection (MISTRA). 2017. C. 107-124.

14. Savchenko A. Fuzzy hyperspace monad. Математичні студіi. 2010. Том 33, № 2. C. 192-198.

15. Savchenko O. A remark on stationary fuzzy metric spaces. Карпатські математичні публікації. 2011. Том 3, № 1. C. 124-129.

16. Savchenko A., Zarichnyi M. Metrization of free groups on ultrametric spaces. Topol. and Appl. 2010. Volume 157, Issue 4. C. 724-729. DOI: https://doi.org/10.1016/j.topol.2009.08.015

17. Savchenko A., Zarichnyi M. Probability measure monad on the category of fuzzy ultrametric spaces. Azerbaijan Journal of Mathematics. 2011. V. 1, No. 1. C. 114-121.

\section{References:}

1. Halushchak, S. I. (2016). Deiaki heometrychni kryvi u sensi d-vidrizka [Some geometric curves in the sense of a d-segment]. Prykarpatskyi visnyk NTSh, Chyslo, 1(33), 157-166 [in Ukrainian].

2. Dovgoshei, A. A., \& Dordovskii, D. V. (2009). Otnoshenie lezhat mezhdu i izometricheskie vlozheniia metricheskikh prostranstv [Betweenness relation and isometric embeddings of metric spaces]. Ukr. mat. zhurn. 61 (10), 1319-1328 [in Russian].

3. Kagan, V. F. (1963). Ocherki po geometrii [Geometry essays]. Moskva: Izdatelstvo Moskovskogo universiteta [in Russian].

4. Kuz'mych, V. I. (2017). Plosko rozmishcheni mnozhyny tochok u metrychnomu prostori [Flat placed sets of points of the metric space]. Visnyk Lvivskoho universytetu. Seriia mekhaniko-matematychna, 83, 58-71 [in Ukrainian].

5. Kuz'mych, V. I. (2019). Heometrychni vlastyvosti metrychnykh prostoriv [Geometric properties of metric spaces]. Ukr. mat. zhurn, 71 (3), 382-399 [in Ukrainian]. 
6. Kuz'mich, V. I. (2019). Formuvannya v shkolyariv ponyat vidstani ta pryamoliniynosti zasobamy metrychnoyi heometriyi [Formation of pupils concepts of distance and straightness by means of metric geometry]. Pedahohichnyy almanakh, 42, 43-50 [in Ukrainian].

7. Kuz'mich, V. I., \& Kuzmich, L. V. (2020). Formuvannia poniattia kuta u shkilnomu kursi matematyky zasobamy metrychnoi heometrii [Formation of the concept of angle in the school course of mathematics by means of metric geometry]. Pedahohichnyi almanakh, 46, 56-63 [in Ukrainian].

8. Kuz'mych, V. I., \& Kuzmych, L. V. (2020). Formuvannia poniat tochky, vidstani ta priamoliniinoho rozmishchennia tochok zasobamy metrychnoi heometrii u 7-9 klasakh [Formation of concepts of point, distance and rectilinear placement of points by means of metric geometry in 7-9 classes]. Fizyko-matematychna osvita, 2 (24), 74-79. doi: https://doi.org/10.31110/2413-1571-2020-024-2-010 [in Ukrainian].

9. Natanson, I. P. (1974). Teoriya funktsiy veshchestvennoy peremennoy [Theory of functions of real variable]. Moskva: Nauka [in Russian].

10. Kuz'mich, V. I., \& Kuzmich, L. V. (2021). Elements of non-Euclidean geometry in the formation of the concept of rectilinear placement of points in schoolchildren. Retrieved from https://doi.org/10.1088/17426596/1840/1/012004 [in English].

11. Kuz'mich, V. I., \& Savchenko, A. G. (2019). Geometric relations in an arbitrary metric space. Matematychni studii, 52(1), 86-95 [in English].

12. Lénárt, I. (2020). The Algebra of Projective Spheres on Plane, Sphere and Hemisphere. J. of Appl. Math. and Phys., 10 (8), 2286-2333 [in English].

13. Lénárt, I., \& Rybak, A. (2017). Comparative Geometry in Primary and Secondary School. The Pedagogy of Mathematics: Is There a Unifying Logic? Johannesburg: Mapungubwe Institute for Strategic Reflection (MISTRA), 107-124 [in English].

14. Savchenko, A. (2010). Fuzzy hyperspace monad. Matematychni studii, 33 (2), 192-198 [in English].

15. Savchenko, O. (2011). A remark on stationary fuzzy metric spaces. Karpatski matematychni publikatsiyi, 3 (1), 124-129 [in English].

16. Savchenko, A., \& Zarichnyi, M. (2010). Metrization of free groups on ultrametric spaces. Topol. and Appl., 157 (4), 724-729 [in English].

17. Savchenko, A., \& Zarichnyi, M. (2011). Probability measure monad on the category of fuzzy ultrametric spaces. Azerbaijan Journal of Mathematics, 1 (1), 114-121 [in English].

Kuz'mich V.I., orcid.org/0000-0002-8150-3456

Kuzmich L. V., orcid.org/0000-0002-6727-9064

Savchenko A. G., orcid.org/0000-0003-4687-5542

\section{THE USE OF ELEMENTS OF GEOMETRY \\ DURING THE STUDY METRIC SPACES BY STUDENTS}

The study of metric spaces students of physical and mathematical specialties in higher education institutions begin, as a rule, in the second year, when studying the functions of several variables. This study is largely devoted to the differential and integral properties of these functions in different metric spaces.

The paper proposes the use of elements of metric geometry to deepen knowledge of the properties of metric spaces in their study by students in physical and mathematical specialties of pedagogical direction. This approach is due to the rapid development of metric geometry in modern mathematics and its widespread use in various fields of science and economics. Much of the material of classical Euclidean geometry can be represented in the form of analytical relationships between its basic concepts: point, distance between points, angle, segment. An example here is the classical Pythagorean theorem on the relationship between the lengths of the sides of a right triangle.

In this paper, based on the axioms of the distance between the points of the metric space, some analytical relations are given that are geometric in Euclidean geometry. Thus, there is a possibility 
of geometric structuring of metric spaces. This allows students to study these spaces from a geometric point of view, building in them images of classical geometric concepts.

Part of the proposed material, due to its simplicity, can be used when working with students in classes with in-depth study of mathematics in secondary education. To this end, the paper considers the specific definitions of the rectilinear location of the points of the metric space, the angle formed by the three points of space and its angular characteristics. They greatly simplify the perception of these results and allow their design in the school course of mathematics.

Key words: general secondary education institutions, profile level of education, extracurricular work in mathematics, geometric competence.

Дата надходження статті: 17.05.2021 p. Рецензент: доктор педагогічних наук, професор Кузьменков С. Г.

УДК 373.016:53-047.42

DOI https://doi.org/10.37915/pa.vi49.257

Полетило С. А. ,

orcid.org/0000-0003-4919-1891

\section{ЕКСПЕРИМЕНТАЛЬНІ ЗАДАЧІ 3 ФІЗИКИ В ЗАГАЯЬНООСВІТНІХ НАВЧАЯЬНИХ ЗАКЛАДАХ ТА ЇХ КЛАСИФІКАЦЇ̈}

У статті на основі вивчення публікацій науковців та врахування думок учителів загальноосвітніх навчальних закладів доведено потребу в нових підходах до класифікації експериментальних задач з фізики. Автор відносить до експериментальних задач ті, дані для отримання розв'язання яких беруться з експерименту. Обьрунтовано, що без наведених класифікацій експериментальних задач вчителі дотримуються лише одного підходу, що не сприяе зростанню інтересу учнів до експериментування.

Розглянуто чотири класифікації експериментальних задач з фізики: за програмним обсягом; за методами розв'язування; за метою використання; за використанням приладів. Кожна з класифікацій поділяе експериментальні задачі на види. Зокрема, класифікація за програмним обсягом розрізняе задачі двох типів: які торкаються лише однієї програмної теми, які охоплюють кілька програмних тем. Класифікація за методами розв'язання допускає такий поділ експериментальних задач: розв'язання яких потребуе одного методу визначення Фізичної величини, розв'язання яких допускае використання кількох методів визначення однієї і тієї ж величини. Класифікаціл задач за метою використання: ті, щзо слугують закріпленню вивченого матеріалу; ті, що орієнтовані на використання фізичних знань у життевих ситуаціях. Класифікація за використанням приладів: звичні (розв'язання яких шукають із допомогою конкретних приладів; творчі (для розв'язання яких пропонуеться підібрати устаткування із наявного); дослідницькі (розв'язання яких потребуе врахування всіх можливих факторів визначення фізичної величини). Для кожної класифікацї̈ наведено конкретні приклади, які ілюструють їх використання в навчанні фізики. Показано, щцо запропоновані класифікації експериментальних задач дають змогу вчителеві конструювати нові моделі уроків фізики; з'являється можливість добирати експериментальні задачі, які забезпечать формування в учнів багатоваріантності думки та зростання їхнього інтересу до експериментування. Використовуеться вся множина методів розв'язування такого роду задач, наближаючи изим учнів до розуміння важливості експериментального методу науки; формуеться сучасний науковий тип мислення.

*C) Полетило C. A.

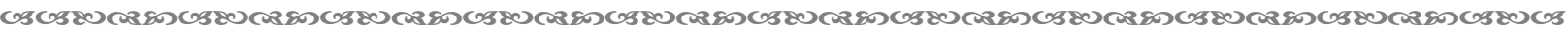

